\title{
The Relationship of Self-efficacy Sources and Metacognitive Reading Strategies: Mediating Role of Reading Self-efficacy Beliefs
}

\author{
M. Waleed Shehzad ${ }^{1}$, Dr. Mohd Hilmi bin Hamzah ${ }^{2}$, Dr. Rafizah Mohd Rawian ${ }^{3}$ \\ ${ }^{1}$ PhD Scholar | School of Languages, Civilization, and Philosophy | UUM College of Arts \\ and Sciences Universiti Utara Malaysia \\ ${ }^{2}$ Senior Lecturer | School of Languages, Civilisation and Philosophy | UUM College of Arts \\ and Sciences, Universiti Utara Malaysia \\ ${ }^{3}$ Senior Lecturer | School of Languages, Civilisation and Philosophy | UUM College of Arts \\ and Sciences, Universiti Utara Malaysia \\ Email: waleedshehzad@yahoo.com
}

\begin{abstract}
This research article presents a conceptual model of the proposed study involving a relationship between self-efficacy sources and metacognitive reading strategies by employing reading self-efficacy beliefs as a mediating variable. Initially, this paper provides a brief background of the variables involved in the study. Furthermore, it gives an insight into the problems faced by the Saudi Preparatory Year Programme (PYP) students regarding employing metacognitive reading strategies while reading. There are three main research objectives of the current study. Firstly, to determine the correlation between self-efficacy sources and self-efficacy beliefs. Secondly, to determine the correlation between self-efficacy beliefs and metacognitive reading strategies. Lastly, to determine the mediating role of selfefficacy beliefs between self-efficacy sources and metacognitive reading strategies. Additionally, three hypotheses are generated on the basis of the reviewed literature. Lastly, it is hoped that the findings of this study would be beneficial for the students, teachers, policy makers and syllabus designers.
\end{abstract}

Keywords: Self-efficacy Sources, Reading Self-efficacy Beliefs, Metacognitive Reading Strategies, Conceptual model

\section{Introduction}

Out of all the four English language skills i.e. listening, speaking, reading and writing, reading skill is considered as the most important due to the reason that it affects the academic achievement to a large extent (Grabe, 1991; Johns, 1981). It has been only few decades ago that the researchers have started to look at the role being played by the cognition in the complex process of reading (Garner, 1987; Goodman, 1967; Grabe, 2010). 
To assist the reading comprehension process, cognitive strategies are used i.e. reading the challenging text again, reducing the reading speed, skimming, recollecting the prior knowledge for the successful accomplishment of reading comprehension of the text. However, only the awareness of cognitive strategies is not enough for the readers. Rather, for the successful reading comprehension, the readers must know how to use these cognitive strategies and how to assess the usefulness of the cognitive strategies being applied (Anderson, 1991). The process of thinking involved while using these cognitive strategies are called metacognitive reading strategies (Anderson, 2003; Mokhtari \& Reichard, 2002; Mokhtari \& Sheorey, 2002).

Metacognitive reading strategies have emerged from the 'theory of metacognition' presented by a well-known psychologist, John Flavell in 1979. Metacognition denotes "knowledge and cognition about cognitive phenomena" (Flavell, 1979, p. 906). The definition of metacognition can be segregated into two parts: (a) knowledge of cognition i.e. reading a text, recollection of thoughts, and learning, and (b) regulation of knowledge (e.g. plotting and scrutinizing) that control thinking (Jacobs \& Paris, 1987). The concept of metacognition will be explained in detail in section 2.6.

There are many researchers who are of the view that the metacognitive strategies enhance the reading competence of the readers (Yuksel \& Yuksel, 2012; Ahmadi, Ismail, \& Abdullah, 2013; Al-Sobhani, 2013; Tavakoli; 2014; Magogwe, 2013; Hong-Nam, 2014; Zhang \& Seepho, 2013; Memis \& Bozkurt, 2013; Phakiti, 2006; Kummin \& Rahman, 2010). Self-efficacy is an important construct in research field. It has been revealed from the metaanalysis of more than 100 experimental studies that out of nine frequently researched psychosocial variables, self-efficacy was the most powerful predictor of learners' academic accomplishments (Artino, 2012). Due to its utmost importance in research field, the current research would make use of this variable. Thus, the next paragraph talks about the selfefficacy generally and reading self-efficacy particularly as the latter serves as the mediating variable in the present study.

In the 'Social cognitive theory', presented in 1986, Bandura $(1986,1997)$ has developed the concept of self-efficacy which denotes to the beliefs of the individual to accomplish a specific task. The definition of self-efficacy beliefs has been given by Bandura (1986) as "people's judgments of their capabilities to organize and execute courses of action required to attain designated types of performances". As the current study focused on reading thus, the variable under consideration is reading self-efficacy. Reading self-efficacy beliefs 
denote to learner's appraisals about their reading capabilities i.e. how confident they are about achieving a specific reading task. Reading self-efficacy beliefs are influenced by the level of performance being achieved in the similar tasks by the readers; this contains any accompanying, response and reassurance received from the teacher (Wigfield, Guthrie, Tonks $\&$ Perencevich, 2004).

There are four sources by which the self-efficacy beliefs are being influenced i.e. mastery experience, vicarious experience, verbal persuasion, and physiological/emotional state (Bandura, 1986). Mastery experience includes the past experiences being experienced by the individual regarding individual's successes and failures. This source of self-efficacy is considered as the most influential as compared to the other three sources. Self-efficacy beliefs gets boosted by successes whereas, it gets lowered when one faces failures. In addition to one's personal experiences, other individuals' experiences, particularly peers' experiences become the second source of self-efficacy beliefs i.e. vicarious experience. In other words, one can observe other successful peers and their success can persuade one to believe that one can accomplish similar task. Verbal persuasion is regarded as the third source of self-efficacy and it includes feedback from the significant people in the life of an individual i.e. parents, peers and teachers. The feedback can influence individual's performance. Lastly, physiological/emotional state like anxiety and exhaustion can affect one's self-efficacy beliefs (Bandura, 1986).

It is anticipated that the Saudi students' should be proficient in the use of English language when they reach university level since they have been learning English language for at least 6 years in schools (Alhawsawi, 2014; Al-Johani, 2009; Rajab, 2013). However, the level of reading of those students still remains unsatisfactory when they reach university level (Ismail, 2014). Regrettably, the level of reading of Saudi students is extremely low as revealed by the International English Language Testing Service's (2015) IELTS test reports. Out of 9 bands, the average bands acquired by the Saudi students in reading skills were 4.8 and 3.7 in academic and general categories respectively.

There are many researchers who are of the view that the poor level of reading of Saudi students after the completion of school education is due to the fact that they memorize and do rote learning just to pass the exam and therefore, reading strategies are being neglected (Alkubaidi, 2014; Almutairi, 2008; Alrabai, 2014, 2016; Fareh, 2010; Rajab, 2013; AlSeghayer, 2014; Elyas \& Picard, 2010). Al-Jarf (2007), is of the view that the Saudi students do not excel in reading due to the non-challenging reading activities and as a consequence the 
development of cognitive and metacognitive capabilities is affected. It can be speculated from the arguments of the above studies that the use of the reading strategies by the Saudi students is limited rather they just memorize everything to pass the exams.

Metacognitive strategies are of utmost importance for the reading comprehension. The use of metacognitive strategies has been recommended by the researchers to enrich the comprehension of reading (Eilers \& Pinkley, 2006; Jitendra, Burgess, \& Gajria, 2011; Law, 2009; Poole, 2011). At a very tender age of eight to ten years, metacognitive skills or strategies start developing among children and these skills keep on developing in the coming years (Berk, 2003; Veenman \& Spaans, 2005; Veenman, Wilhelm \& Beishuizen, 2004). However, in the Saudi Arabian context, firstly, the students are not given much attention regarding metacognitive reading strategies rather they are taught surface strategies for reading purposes till the end of secondary school level (Al-Jarf, 2007). Thus, it can be speculated that they are not exposed to metacognitive knowledge till the age of 18. Secondly, they are exposed to learning of English language very late i.e. $6^{\text {th }}$ grade (Al-Johani 2009; Al-Mansour, 2009; Gawi, 2012). As a consequence of these two major problems, when the EFL students reach the university level, generally they are quite weak in comprehending the text and ultimately face problems in reading the text because they apply reading strategies that are helpful in the surface reading but not very helpful in the reading of university level books (Ismail, 2014; Hermida, 2009).

From the above arguments it can be speculated that a lot of precious time i.e. 8 to 10 years, of Saudi school students for learning or development of metacognitive skills is probably not utilized effectively. Thus, to enhance the level of English proficiency of Saudi students in all the four skills of English language, they need to attend Preparatory Year Programme (PYP), before they enter the university to pursue undergraduate studies (AlShumaimeri, 2013). This situation has compelled the researcher to conduct the research on Saudi PYP university students to know their level of awareness in using metacognitive reading strategies by manipulating the context of PYP.

The review of the literature has shown that there is a relationship between metacognitive reading strategies and self-efficacy (Kargar \& Zamanian, 2014; Nosratinia, Saveiy \& Zaker, 2014; Yailagh, Birgani, Boostani \& Hajiyakhchali, 2013; Tuncer \& Dogan, 2016; Uçar, 2016; Zarei \& Gilanian, 2015; Tavakoli \& Koosha, 2016; Taghinezhad, Dehbozorgi \& Esmaili, 2015; Yang \& Wang, 2015; Keskin, 2014). Whereas, there is scarcity of studies which indicate the relationship between self-efficacy sources (mastery experience, 
vicarious experience, verbal persuasion, and physiological state) and metacognitive reading strategies. Therefore, the current study attempts to determine the relationship between selfefficacy sources (mastery experience, vicarious experience, verbal persuasion, and physiological state) and metacognitive reading strategies used by the Saudi PYP students, by employing reading self-efficacy as a mediator.

There are several studies in which self-efficacy was used as a mediator and the findings of these studies have indicated that self-efficacy mediates the relationship among diverse range of variables (Phan \& Ngu, 2016; Keskin, 2014; Diseth, 2011; Fast et al., 2010; Coutinho \& Neuman, 2008; Bates \& Khasawneh, 2007; Pajares, Hartley \& Valiante, 2001). In the present study, 'reading self-efficacy beliefs' is being employed as a mediator. The rationale of employing reading self-efficacy as a mediator is that in the previous literature there is an extreme dearth of studies which indicate the relationship between self-efficacy sources (mastery experience, vicarious experience, verbal persuasion, and physiological state) and metacognitive reading strategies. Yet, a strong relationship is found between self-efficacy sources and reading self-efficacy and also between reading self-efficacy and metacognitive reading strategies. According to Preacher, Rucker and Hayes (2007), mediation (M) is tending to occur if there is no direct relationship between independent variable (X) and dependent variable (Y). In other words, $\mathrm{X}$ influences $\mathrm{Y}$ only if $\mathrm{X}$ influences $\mathrm{M}$ and as a result $\mathrm{M}$ influences $Y$. Thus, it can be assumed that reading self-efficacy mediates the relationship between self-efficacy sources and metacognitive reading strategies as shown in Figure 1.

\section{Figure 1: Conceptual Model}

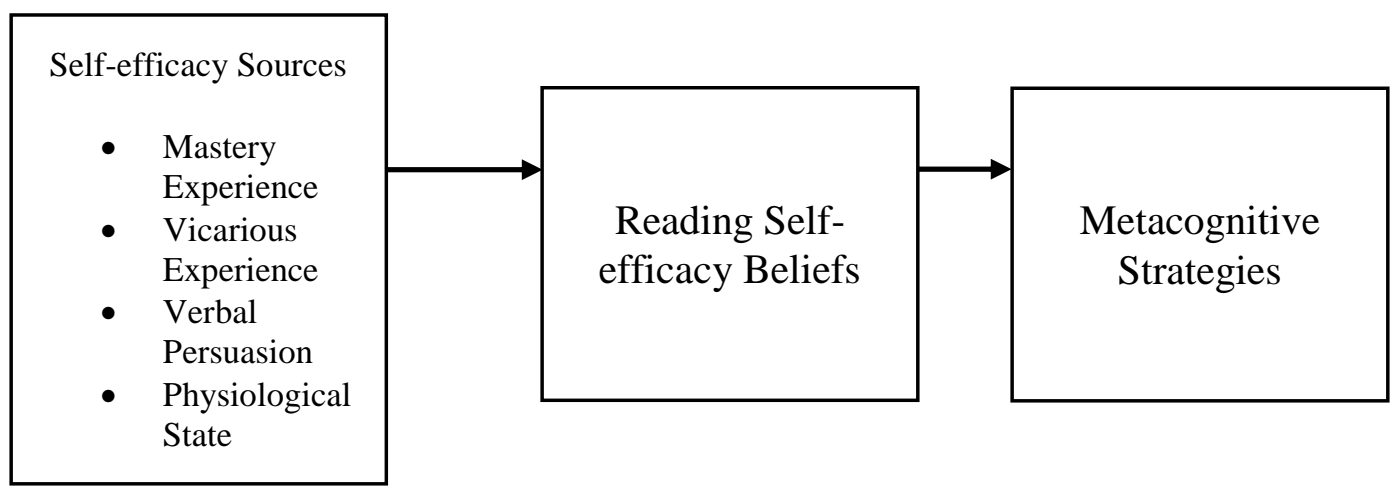

The objectives of the study are given below;

1) To determine the extent of correlation between four self-efficacy sources and reading self-efficacy beliefs among Saudi PYP students. 
a. To determine the extent of correlation between mastery experience and reading self-efficacy beliefs among Saudi PYP students.

b. To determine the extent of correlation between vicarious experience and reading self-efficacy beliefs among Saudi PYP students.

c. To determine the extent of correlation between verbal persuasion and reading self-efficacy beliefs among Saudi PYP students.

d. To determine the extent of correlation between physiological state and reading self-efficacy beliefs among Saudi PYP students.

2) To determine the extent of correlation between reading self-efficacy beliefs and metacognitive reading strategies used by Saudi PYP students.

3) To determine the mediating role of reading self-efficacy beliefs between four selfefficacy sources and metacognitive reading strategies used by Saudi PYP students.

\section{Literature Review}

\section{A. Relationship between Self-efficacy Sources and Self-efficacy Beliefs}

Various researchers have conducted research regarding sources of self-efficacy in diverse academic disciplines i.e. (Zarei \& Naghdi, 2017; Cantrell, Correll, Clouse, Creech, Bridges \& Owens, 2013; Williams, 2017; Lin \& Tsai, 2017; Fong \& Krause, 2014; Lin, 2016; Arslan, 2013; Phan, 2012; Yurt, 2014; Phan \& Ngu, 2016; Amanda \& Ellen, 2015; Bryant, 2017).

Zarei and Naghdi (2017) examined the probable variations among the sources of selfefficacy as the predictors of EFL students' accomplishments. The sample of the study was 219 EFL students. The study was quantitative in nature, consequently, questionnaires were used as data collection instruments. Findings revealed that only mastery experience is positively and significantly related to the students' accomplishments. All the other three sources of self-efficacy have not shown significant relationship.

Similarly, Cantrell et al. (2014) carried out a study on self-efficacy beliefs and the sources of self-efficacy beliefs. The objective of the study was to determine the self-efficacy beliefs and sources of self-efficacy beliefs among the two groups i.e. the students who were placed in developmental courses and the students who were placed in credit bearing courses. The sample of the study was 100 students including 47 females and 53 males. The findings have shown lower levels self-efficacy among the students of developmental reading courses as compared to the other group. Moreover, when sex and ethnicity were controlled, the variations of self-efficacy sources between two groups have shown results that were not 
Pakistan Journal of Humanities and Social Sciences, 6(1), 2018

significant statistically. However, the participants of both the groups are of the view that out of all the sources, mastery experiences affect reading self-efficacy the most. Likewise, Fong and Krause (2014) conducted a research to determine the level of self-efficacy and sources of self-efficacy among college students. The sample of the study was 49 students and they were divided into two groups i.e. achievers $(n=36)$ and non-achievers $(n=13)$. In this study the authors have added self-regulated learning as an additional source along with the four hypothesized sources of self-efficacy. Mixed-methods research design was employed in this study. The findings regarding non-achievers have highlighted the significance of mastery experience. However, it was found that both the groups were almost same in terms of selfefficacy but achievers' group had more verbal persuasion and mastery experience as compared to other group.

Cantrell et al. (2013) recommended that research needs to be done to find the relationship between self-efficacy sources and reading self-efficacy which will consequently enrich the insights regarding the self-efficacy construct.

Amanda and Ellen (2015) explored the level of self-efficacy sources and self-efficacy beliefs in the English and mathematics domain. The sample of the study was 2,511 upper elementary and middle school students. The study was conducted by employing mixedmethods design. The results have disclosed that the two sources were most frequently found i.e. social persuasion and mastery experience. Moreover, it was found that girls get influenced by social sources more than boys. In the same way, Yurt (2014) investigated the relationship between self-efficacy sources and the accomplishment in mathematics subject. The sample of the study consisted of $3507^{\text {th }}$ grade students from different schools. Study was quantitative in nature. The finding has revealed that all the sources have been positively correlated to the achievement except vicarious experience.

Amanda and Ellen (2015) and Yurt (2014) have similarities due to the reason that both have done research on mathematics domain students. However, former has used the mixed-methods research design and latter has used quantitative design. The findings of Amanda and Ellen's (2015) study can be considered more reliable due to its large sample size.

Similarly, Williams (2017) examined the sources of self-efficacy beliefs among the children in the field of science. The sample of the study consisted of 182 school children. Mixed-methods research design was employed and the tools used for data collection were focus groups interviews, individual interviews, and questionnaires. The results of the study 
indicated that all the sources of self-efficacy can be found among children, however, boys were mostly influenced by mastery experience whereas, the girls were mostly influenced by a mixture of two sources i.e. physiological states and vicarious experience. Similarly, Lin and Tsai (2017) investigated the self-efficacy beliefs and self-efficacy sources among Taiwanese high-school students in the area of science. The sample consisted of 130 high-school students. The study was quantitative in nature. The findings indicated a significant positive relationship between all the sources and the self-efficacy beliefs but there are two sources which have played substantial role i.e. mastery and vicarious experience. In terms of gender, social persuasion source has influenced the female students the most, whereas, male students were mostly influenced by vicarious experience.

Both the studies i.e. Williams (2017) and Lin and Tsai (2017) are comparable due to the fact that both the studies were conducted on the students of science domain. However, Williams' (2017) study used mixed-methods research design as opposed to Lin and Tsai's (2017) study which employed quantitative research design. Both the studies have shown similar findings i.e. all the self-efficacy sources were found in the participants.

Lin (2016) carried out a study to know the relationship between three kinds of selfefficacy i.e. learning self-efficacy, computer self-efficacy, and programming self-efficacy and the sources of self-efficacy on the basis of gender and persistence among university students. The sample of the study was 1,073 university undergraduate students majoring in computing science. Quantitative research design was employed in this. The findings revealed that gender had no significant effect on the self-efficacy and self-efficacy sources. Whereas, all kinds of self-efficacy and sources were significantly influenced by the persistence levels apart from computer self-efficacy and physiological state. Furthermore, all the three kinds of selfefficacy were influenced by the sources of self-efficacy differently.

Also, Arslan (2013) examined the relationship between students' sources of selfefficacy and their learning style, grade level, gender, Socio-Economic Status (SES), and academic achievement. The sample of the study was 984 secondary school students. It was a quantitative study. The results revealed significant relationships between sources of students' self-efficacy and their learning style, grade level, gender, Socio-Economic Status (SES), and academic achievement.

Phan (2012) investigated the effect of self-efficacy sources on the students' selfefficacy beliefs in English and mathematics domain by using latent growth modeling. The sample of the study was $3393^{\text {rd }}$ and $4^{\text {th }}$ grade school students. Latent growth modeling 
revealed that the students' level of self-efficacy in both the subjects increased with the passage of time. Furthermore, regarding self-efficacy sources, it was found that three sources i.e. mastery experience, vicarious experience, verbal persuasion have shown significant positive relationship. While students' physiological states were negatively correlated to growth of self-efficacy beliefs. Additionally, it was also revealed that out of all the three sources, mastery experience was the main predictor of self-efficacy beliefs. Similarly, Phan and Ngu (2016) investigated the relationship between self-efficacy sources and academic achievement by employing self-efficacy as a mediator by using sequential predictive model. The sample of the research was 328 elementary school students. The data was collected at 3 different times of one calendar year. The results at time 1 indicated that out of four sources only vicarious and mastery experience showed positive significant relationship with selfefficacy. At Time 2, only mastery experience indicated significant relationship. At Time 3, three sources remained significant i.e. mastery experience, physiological state and verbal persuasion remained significant. Whereas, self-efficacy indicted significant relationship with achievement during all the three observations.

Both the studies i.e. Phan (2012) and Phan and Ngu (2016) are analogous due to two reasons. Firstly, both the studies were conducted on the elementary level school students. Secondly, the sample size was almost same. Thirdly, both studies have used growth modeling in which data was collected various times.

Similarly, Bryant (2017) explored the influence of self-efficacy sources experiences and evolving self-efficacy sources on students' motivation. Sample was 18 school students of grade 10, 3 school teachers, school principal and a guidance counselor. Study was purely qualitative in nature and interviews were used to collect data. Findings revealed that selfefficacy beliefs were developed in every student due to the development of self-efficacy sources generally and mastery experience particularly. It was also revealed that efficacy sources' growth occurred due to the positive and negative experiences being experienced by them in their life. Finally, it was revealed that the development of motivation depends upon perceived self-efficacy of the students that was gained from all the four sources.

Based on the studies reviewed above, following hypothesis can be generated:

$\mathbf{H}_{1}$ : There is a positive significant relationship between self-efficacy sources and selfefficacy beliefs 


\section{B. Relationship between Reading Self-efficacy beliefs and Metacognitive Reading Strategies}

There are many studies which indicate the relationship between metacognitive reading strategies and self-efficacy beliefs. There are several researchers who have done research regarding self-efficacy beliefs and metacognitive strategies i.e. (Li \& Wang, 2010; Naseri \& Zaferanieh, 2012; Kargar \& Zamanian, 2014; Nosratinia, Saveiy \& Zaker, 2014; Yailagh et al., 2013; Javanmard et al., 2012; Tuncer \& Dogan, 2016; Uçar, 2016; Y1lmaz, 2010; Zarei \& Gilanian, 2015; Tavakoli \& Koosha, 2016; Taghinezhad et al., 2015; Yang \& Wang, 2015; Keskin, 2014; Shang, 2010).

Tuncer and Dogan (2016) conducted a study among the 271 Turkish EFL engineering students in which the relationship between metacognitive strategies awareness, self-efficacy beliefs and language anxiety was investigated. The results revealed that there is a negative significant relationship between self-efficacy and metacognitive strategies. Uçar (2016) also conducted the study in Turkey to find the relationship between self-efficacy and the usage metacognitive reading strategies by 150 University Turkish EFL students studying in foreign language department. The instruments used in the study to find the level of self-efficacy and the strategies used by the students were 'self-efficacy scale' adapted from Gahungu (2007) and 'scale for language learning strategy use' developed by Oxford (1990) respectively. The findings of the study revealed that there is a positive significant relationship between selfefficacy and metacognitive strategies.

Similarly, Y1lmaz (2010) like the above two studies investigated the relationship between metacognitive strategies that Turkish University students and the self-efficacy beliefs. 140 university students participated in the study and all were majoring in English. He also added additional variables i.e. gender and language proficiency. Findings revealed that more proficient students used metacognitive strategies more frequently than less proficient students. In terms of gender, both male and female students have used the metacognitive strategies equally. Finally, it was revealed that there is a significant positive relationship between the use of metacognitive strategies and self-efficacy beliefs.

In the same way, Zarei and Gilanian (2015) have investigated that how different strategies including metacognitive strategy are related to different types of self-efficacy i.e. self-regulatory, general and academic self-efficacy. The sample included 147 Iranian university students majoring in English. It was found that metacognitive strategies were positively correlated with academic self-efficacy. 
Pakistan Journal of Humanities and Social Sciences, 6(1), 2018

Similarly, Tavakoli and Koosha (2016) conducted a study on the effect of metacognitive strategy instruction on the self-efficacy and reading comprehension of the English language. The sample of the study was 100 Iranian university students who were majoring in English. The instruments used for collection of data were Questionnaires and Reading comprehension test. Sample was divided into experimental and control group. Experimental group was exposed to metacognitive strategies instruction. The results of the study revealed that there is a positive and significant relationship of metacognitive instruction with self-efficacy and reading comprehension. Moreover, experimental group outperformed the control group.

Similarly, Taghinezhad, Dehbozorgi and Esmaili (2015) conducted a study on 90 Iranian EFL upper-intermediate level students. The researcher has divided the sample into two groups i.e. experimental and control group. Metacognitive strategies were taught to experimental group. The findings indicated that the experimental group outperformed the control group. Moreover, both male and female students have used the metacognitive strategies on almost equal basis. Finally, it was found that learners' self-efficacy beliefs were positively correlated with the teaching of metacognitive reading strategies.

In the same way, Yang and Wang (2015) investigated the relationship between selfefficacy, language learning strategies including metacognitive strategies and strategy instructions. The sample consisted of 78 Taiwanese ESL college students. The findings revealed that as compared to strategy instruction the correlation between self-efficacy and metacognitive strategies are more significant. Furthermore, the students started applying more strategies after the strategy instruction.

All the three studies i.e. Tavakoli and Koosha (2016), Taghinezhad et al. (2015) and Yang and Wang (2015) are similar to each other due to the fact that intervention of metacognitive strategies instruction was done on the students. The results of all the three studies showed that metacognitive strategies instruction had a positive significant influence on self-efficacy and use of strategies.

Jee (2015) investigated the use of learning strategies with the self-efficacy beliefs. The sample of the study was 92 Korean university students divided into two groups, i.e. high and low-achievement groups. The instrument to measure the use of language strategies was SILL by Oxford (1990) and for measuring self-efficacy beliefs, Jee (2015) developed a selfefficacy questionnaire based on SILL (Oxford, 1990). The outcomes revealed that there is a positive significant relationship between metacognitive strategies and self-efficacy beliefs. 
Moreover, low-achievement students outperformed the high-achievement students in terms of using strategies.

Contrary to the majority of the previous studies being reviewed i.e. Zarei and Gilanian (2015), Jee (2015), Tavakoli and Koosha (2016), Y1lmaz (2010), Tuncer and Dogan's (2016) and Uçar's (2016) which were conducted on university level students, Rahimi and Abedi (2014), conducted a study on high school students. This study was conducted to know the relationship between listening metacognitive awareness and listening self-efficacy beliefs among 371 students. The outcomes revealed that the listening selfefficacy is positively and significantly related with metacognitive awareness of listening strategies.

Similarly, Yailagh, Birgani, Boostani and Hajiyakhchali (2013) also conducted research on high school students. The relationship between self-efficacy and metacognition was studied in this study. The sample consisted of 230 female high school students. It was found that the self-efficacy and metacognition are positively correlated to each other.

However, the study by Yailagh et al. (2013) can be criticized due to the reason that only female students were included in the sample. Therefore, generalizing the results of the current study to the other gender could be dubious.

Also, Javanmard, Hoshmandja and Ahmadzade (2012) investigated the relationship of self-efficacy beliefs, cognitive strategies and metacognitive strategies with academic achievement. The sample of the study was 322 high school students. The results found that cognitive strategies, metacognitive strategies and self-efficacy have a significant relationship with academic achievement.

Nosratinia, Saveiy and Zaker (2014) conducted a research on 150 EFL university students who are majoring in English literature. In this study, relationship between learning strategies use, metacognitive awareness and the perceived self-efficacy of students was determined. The results indicated that there is a positive significant relationship between metacognitive awareness and self-efficacy, self-efficacy and language strategies usage, metacognitive awareness and use of strategies.

Kargar and Zamanian (2014) explored the relationship of reading strategies and selfefficacy beliefs of the EFL Iranian students who are considered as advanced English learners. The sample of the study comprised of 50 students including 28 females and 22 males. Finding indicated positive significant relationship between reading strategies and self-efficacy beliefs. Furthermore, it was revealed that both male and female students were almost equal in terms 
of self-efficacy level and usage of reading strategies. Kargar and Zamanian's (2014) study can be criticized due to its small sample size. Consequently, it could be challenging to deduce the results owing to validity and duplicating issue.

In the same way, Naseri and Zaferanieh (2012) conducted a study to know the relationship of three variables i.e. reading comprehension level, self-efficacy and the use of reading strategies by the students. The sample of this study is 80 students including both male and female students. The results indicated that there is a positive correlation of reading selfefficacy with reading comprehension and metacognitive strategies. Additionally, gender had no significant relationship with self-efficacy and metacognitive strategies.

Zare and Mobarakeh (2011) conducted a research to find the relationship between self-efficacy and the reading strategies i.e. metacognitive, social/affective and cognitive strategies. The sample of the research contained 45 students. The results indicated that selfefficacy beliefs were positively and significantly correlated to metacognitive strategies. Likewise, Li and Wang (2010) investigated the relationship between self-efficacy beliefs and reading strategies including cognitive, metacognitive and social/affective reading strategies. The sample of the study included 182 Chinese first semester University students. The findings revealed a positive significant relationship between self-efficacy beliefs and the use of metacognitive reading strategies. Additionally, it was found that more reading strategies were used by the students whose self-efficacy level is high as compared to low self-efficacious students.

Similarly, Cera, Mancini and Antoniette (2013) conducted a research to know the relationship between metacognition and few other variables i.e. autonomy, self-efficacy and self-regulation. The sample was 130 high school students. The findings indicated a positive correlation between metacognition and the other three variables i.e. self-efficacy, autonomy and self-regulation.

Aydin, Uzuntiryaki and Demirdög en (2011) conducted a study in which they tested the relationship between task value and self-efficacy with metacognitive self-regulation as a mediator. The sample consisted of 518 students studying in a college. Analysis was done by using statistical software i.e. PLS. Findings revealed significant relationship between task value and self-efficacy. Furthermore, the significant influence of metacognition on the selfefficacy beliefs of the students was also found. Likewise, Keskin (2014) investigated the relationship between metacognitive strategies and task value with self-efficacy as a mediator. The sample of the study consisted of 370 middle school students of $5^{\text {th }}, 6^{\text {th }}, 7^{\text {th }}$ and $8^{\text {th }}$ grade. 
Findings revealed that there was a significant relationship between self-efficacy and metacognitive strategies. Additionally, self-efficacy was also significantly correlated to the task value.

Shang (2010) conducted the research on self-efficacy, use of metacognitive reading strategies and reading comprehension. The objectives of the study were to know about the reading strategies being employed most frequently by the students, to know the relationship between reading strategies and the self-efficacy beliefs, and lastly, to know the viewpoints of the students after the reading instruction. The sample included 53 Taiwanese university students including 36 females and 17 males. Mixed-method research has been employed by the researcher to conduct this study. The findings revealed that out of three strategies, metacognitive strategies were used most frequently. Moreover, it was found that there was a positive significant relationship between self-efficacy and reading strategies use. Furthermore, metacognitive strategies were not significantly correlated to reading comprehension. Interviews' results found that what specific strategies students use in different circumstances. Shang's (2010) study is different from all the previous studies being reviewed due to the reason that all the other studies have used quantitative method for conducting research whereas, Shang's (2010) employed mix-methods research. Consequently, the findings of Shang (2010) can be considered more reliable.

Bonyadi, Nikou and Shahbaz (2012) found the relationship between self-efficacy and usage of learning strategies by the students. The participants were chosen from three universities and the sample consisted of 210 students. Findings revealed that the students have used metacognitive strategies most frequently. Additionally, gender had made no significant influence in predicting self-efficacy and use of metacognitive strategies. Lastly, there was no significant relationship between self-efficacy beliefs and metacognitive strategies.

The findings of Bonyadi et al. (2012) are opposite to the findings of all the studies being reviewed due to the fact that Bonyadi et al. (2012) had revealed that there is no significant relationship between two variables.

Based on the review of the above studies, following hypothesis can be generated.

$\mathbf{H}_{2}$ : There is a positive significant relationship between self-efficacy beliefs and metacognitive reading strategies.

\section{Self-efficacy as a Mediator}

There are several studies in which self-efficacy was used as a mediator and the findings of these studies have indicated that self-efficacy mediates the relationship among 
Pakistan Journal of Humanities and Social Sciences, 6(1), 2018

diverse range of variables (Phan \& Ngu, 2016; Keskin, 2014; Diseth, 2011; Fast et al., 2010; Coutinho \& Neuman, 2008; Bates \& Khasawneh, 2007; Pajares, Hartley \& Valiante, 2001).

Phan and Ngu (2016) conducted a study on elementary school students to determine the influence of four self-efficacy sources on academic achievement by employing selfefficacy beliefs as a mediator. It was a longitudinal study which data was gathered in three intervals. In the first interval, two sources, i.e. mastery experience and vicarious experience impacted self-efficacy beliefs. In the second interval, only mastery experience impacted selfefficacy beliefs. Lastly, in the third interval, three sources, i.e. mastery experience, verbal persuasion, and physiological states impacted self-efficacy beliefs. It was also found that selfefficacy beliefs influenced academic achievement across all the three intervals.

Similarly, Keskin (2014) conducted a research on 370 middle school students to determine the impact of metacognitive reading strategies on reading task value by using reading self-efficacy beliefs as a mediating variable. The findings indicated that metacognitive reading strategies had a significant impact on reading self-efficacy beliefs. Further, reading self-efficacy beliefs influenced reading task value significantly. Likewise, Diseth (2011), in his empirical study, included self-efficacy beliefs as a mediator between previous and succeeding achievement. The results indicated that self-efficacy acted as a mediator between both the achievements.

Also, Fast et al. (2010) examined the mediating role of math self-efficacy between classroom environment and math accomplishment. The sample of the study consisted of 1163 upper-elementary school pupils. The findings showed that math self-efficacy successfully mediate the relationship between classroom environment and math accomplishment.

$\mathbf{H}_{3}$ : $\quad$ Reading self-efficacy mediates the relationship between self-efficacy sources and metacognitive reading strategies.

\section{Conclusion}

It can be concluded on the basis of the literature reviewed above that there is a significant relationship between self-efficacy sources and reading self-efficacy beliefs and also between reading self-efficacy beliefs and metacognitive reading strategies. Also, several studies indicated that self-efficacy acts as a mediating variable. However, this paper has a limitation, i.e. it is a conceptual paper and thus, it does not contain empirical findings. Therefore it is recommended that empirical research ought to be done involving these variables in the future. 
It is hoped that this study would be able to give awareness about the use of metacognitive reading strategies to the EFL students generally and the Saudi PYP students particularly. It would be beneficial for the Saudi PYP students specifically because the review of literature has shown that they lack use of reading strategies while learning English in the schools (Alkubaidi, 2014; Almutairi, 2008; Alrabai, 2014, 2016; Fareh, 2010; Rajab, 2013; Al-Seghayer, 2014; Elyas \& Picard, 2010). Therefore, they would come to know about the current strategies being used by them and maybe in the future they would use better strategies by raising their awareness of metacognitive strategies, whenever they come across hurdles in the reading process. Similarly, the present study could be equally beneficial for the EFL Arab learners of other countries because the students in the middle-east share almost the same cultural and educational backgrounds with the EFL students of KSA.

Furthermore, this research might help the English teachers of Saudi Arabia generally and English teachers of the PYP particularly. Hopefully, the results of the research may evoke the teachers to adopt the metacognitive reading strategies in their reading pedagogy and utilize the efficient ones in their class to improve the reading comprehension of the students. Additionally, the findings of the current research could aid the Saudi educational policy makers to compel them to reconsider the current policies and upgrade the presently used teaching pedagogies and the English curriculum so that the teaching of metacognitive reading strategies can be incorporated into the curriculum and consequently influence the strategic competence development among the Saudi learners.

Moreover, it is expected that the outcomes of this research could be beneficial in enhancing the EFL teacher's awareness and knowledge of their learners' psychological attributes and necessities during the language learning development process. Hence, EFL learners could be provided with appropriate support by the teachers that could help them in boosting their reading performance by imparting self-efficacy beliefs in them. Particularly, this research would be helpful for both the students and EFL instructors to get knowledge about the self-efficacy beliefs and to know about the vital role being played by them in relation to the use of metacognitive reading strategies.

Significantly, it is anticipated that the current research would make a contribution by adding valuable findings into the body of literature. Hopefully, it would provide a baseline for the future research of metacognitive reading strategies in terms of self-efficacy beliefs generally and self-efficacy sources particularly. By reviewing the literature, a vital finding regarding theoretical gap has been found that there is an extreme dearth of research to know 
Pakistan Journal of Humanities and Social Sciences, 6(1), 2018

the relationship between the sources of self-efficacy and reading strategies generally and metacognitive reading strategies particularly. Thus, it is worthy to investigate the relationship between metacognitive reading strategies, self-efficacy and self-efficacy sources, instead of investigating them alone. Consequently, this theoretical gap would be filled in the present study by conducting research on the two variables i.e. 'self-efficacy sources' and 'metacognitive reading strategies', for the very first time according to researcher's best knowledge. 


\section{References}

Ahmadi, R. A., Ismail, H. N., \& Abdullah, M. K. (2013). The importance of metacognitive reading strategy awareness in reading comprehension. English Language Teaching, 6(10), 235-249. http://dx.doi.org/10.5539/elt.v6n10p235

Alhawsawi, S. (2014). Investigating student experiences of learning English as a foreign language in a preparatory programme in a Saudi university (Doctoral dissertation, University of Sussex).

Al-Jarf, R. (2007). Developing reading and literacy in Saudi Arabia.

Al-Johani, H. M. (2009). Finding a way forward: the impact of teachers' strategies, beliefs and knowledge on teaching English as a foreign language in Saudi Arabia (Doctoral dissertation, University of Strathclyde).

Alkubaidi, M. A. (2014). The relationship between Saudi English major university students' writing performance and their learning style and strategy use. English Language Teaching, 7(4), 83-95. http://dx.doi.org/10.5539/elt.v7n4p83

Al-Mansour, N. (2009). Bilingualism and the need for early EFL education in the Kingdom of Saudi Arabia. J. King Saud University, 21, 1-12.

Almutairi, N. H. (2008). The influence of educational and socio-cultural factors on the learning styles and strategies of female students in Saudi Arabia. Doctoral Dissertation. University of Leicester, Leicester, UK.

Alrabai, F. (2014). Motivational practices in English as a foreign language classes in Saudi Arabia: Teachers beliefs and learners perceptions. Arab World English Journal, 5(1), 224-246.

Alrabai, F. (2016). Factors underlying low achievement of Saudi EFL learners. International Journal of English Linguistics, 6(3), 21.

Al-Seghayer, K. (2014). The four most common constraints affecting English teaching in Saudi Arabia. International Journal of English Linguistics, 4(5), 17.

Al-Shumaimeri, Y. (2013). The Effect of an Intensive English Language Program on First Year University Students' Motivation. Journal of Educational \& Psychological Sciences, 14(1), 11-32.

Al-Sobhani, Y. A. (2013). Metacognitive reading strategies use by Yemeni EFL undergraduate university students. Frontiers of Language and Teaching, 4, 121-130.

Anderson, N. J. (1991). Individual differences in strategy use in second language reading and testing. The modern language journal, 75(4), 460-472.

Anderson, N. J. (2003). Metacognitive reading strategies increase L2 performance. The Language Teacher, 27(7), 20-22.

Arslan, A. (2013). Investigation of Relationship between Sources of Self-Efficacy Beliefs of Secondary School Students and Some Variables. Educational Sciences: Theory and Practice, 13(4), 1983-1993.

Artino, A. R. (2012). Academic self-efficacy: From educational theory to instructional practice. Perspectives on medical education, 1(2), 76-85.

Bandura, A. (1986). The explanatory and predictive scope of self-efficacy theory. Journal of social and clinical psychology, 4(3), 359-373.

Bandura, A. (1997). Self-efficacy: The exercise of control. Macmillan.

Bates, R., \& Khasawneh, S. (2007). Self-efficacy and college students' perceptions and use of online learning systems. Computers in Human Behavior, 23(1), 175-191.

Berk, L. E. (2003). Child Development (6th ed.). Boston: Allyn and Bacon.

Bryant, S. K. (2017). Self-Efficacy Sources and Academic Motivation: A Qualitative Study of 10th Graders. 
Pakistan Journal of Humanities and Social Sciences, 6(1), 2018

Butz, A. R., \& Usher, E. L. (2015). Salient sources of early adolescents' self-efficacy in two domains. Contemporary Educational Psychology, 42, 49-61.

Cantrell, S. C., Correll, P., Clouse, J., Creech, K., Bridges, S., \& Owens, D. (2013). Patterns of self-efficacy among college students in developmental reading. Journal of College Reading and Learning, 44(1), 8-34.

Coutinho, S. A., \& Neuman, G. (2008). A model of metacognition, achievement goal orientation, learning style and self-efficacy. Learning Environments Research, 11(2), $131-151$.

Diseth, A. (2011). Self-efficacy, goal orientations and learning strategies as mediators between preceding and subsequent academic achievement. Learning and Individual Differences, 21(2), 191-195.

Eilers, L. H., \& Pinkley, C. (2006). Metacognitive strategies help students to comprehend all text. Reading Improvement, 43(1), 13.

Elyas, Tariq, \& Picard, Michelle. (2010). Saudi Arabian educational history: impacts on English language teaching. Education, Business and Society: Contemporary Middle Eastern Issues, 3(2), 136-145.

Fareh, S. (2010). Challenges of teaching English in the Arab world: Why can't EFL programs deliver as expected? Procedia-Social and Behavioral Sciences, 2(2), 3600-3604. http://dx.doi.org/10.1016/j.sbspro. 2010.03.559

Fast, L. A., Lewis, J. L., Bryant, M. J., Bocian, K. A., Cardullo, R. A., Rettig, M., \& Hammond, K. A. (2010). Does math self-efficacy mediate the effect of the perceived classroom environment on standardized math test performance? Journal of Educational Psychology, 102(3), 729.

Flavell, J. H. (1979). Metacognition and cognitive monitoring: A new area of cognitivedevelopmental inquiry. American psychologist, 34(10), 906.

Fong, C. J., \& Krause, J. M. (2014). Lost confidence and potential: a mixed methods study of underachieving college students' sources of self-efficacy. Social Psychology of Education, 17(2), 249-268.

Garner, R. (1987). Metacognition and reading comprehension. Ablex Publishing.

Gawi, E. M. K. (2012). The effects of age factor on learning English: A case study of learning English in Saudi schools, Saudi Arabia. English Language Teaching, 5(1), 127.

Goodman, K. S. (1967). Reading: A psycholinguistic guessing game. Literacy Research and Instruction, 6(4), 126-135.

Grabe, W. (1991). Current developments in second language reading research. TESOL quarterly, 25(3), 375-406.

Grabe, W. (2010). Fluency in reading--Thirty-five years later. Reading in a foreign language, $22(1), 71$

Hermida, D. (2009). The importance of teaching academic reading skills in first-year university courses.

Hong-Nam, K. \& Page, L. (2014). ELL high school students' metacognitive awareness of reading strategy use and reading proficiency. Teaching English as a Second or Foreign Language: The Electronic Journal for English as a Second Language, 18(1). Retrieved from http://www.tesl-ej.org/wordpress/issues/volume18/ ej69/ej69a4/

IELTS Partners (British Council, IDP: IELTS Australia Pty Ltd., and Cambridge English Language Assessment). (2015). IELTS Researchers: Test Taker Performance 2015. Retrieved from http://www.ielts.org/researchers/ analysis_of_test_data/test_taker_performance_2015.aspx

Ismail, N. M. (2014). Effectiveness of a metacognitive reading strategies program for improving low achieving EFL readers. International Education Studies, 8(1), 71. 
Jacobs, J. E., \& Paris, S. G. (1987). Children's metacognition about reading: Issues in definition, measurement, and instruction. Educational Psychologist, 22(3-4), 255-278.

Javanmard, A., Hoshmandja, M., \& Ahmadzade, L. (2012). Investigating the relationship between self-efficacy, Cognitive and metacognitive strategies, and academic selfhandicapping with academic achievement in male high school students in the Tribes of Fars Province. Journal of Iife Science and Biomedicine, 3(1), 27-34.

Jitendra, A. K., Burgess, C., \& Gajria, M. (2011). Cognitive strategy instruction for improving expository text comprehension of students with learning disabilities.

Johns, A. M. (1981). Necessary English: A faculty survey. TESOL Quarterly, 15(1), 51-57.

Kargar, M., \& Zamanian, M. (2014). The relationship between self-efficacy and reading comprehension strategies used by Iranian male and female EFL learners. International Journal of Language Learning and Applied Linguistics World, 7(2), 313-325.

Keskin, H. K. (2014). A path analysis of metacognitive strategies in reading, self-efficacy and task value. International Journal of Social Science and Education, 4(4), 798-808.

Kummin, S., \& Rahman, S. (2010). The relationship between the use of metacognitive strategies and achievement in English. Procedia - Social and Behavioral Sciences, 7, 145-150. http://dx.doi.org/10.1016/j.sbspro.2010.10.021

Law, Y. K. (2009). The role of attribution beliefs, motivation and strategy use in Chinese fifth-graders' reading comprehension. Educational research, 51(1), 77-95.

Li, Y., \& Wang, C. (2010). An empirical study of reading self-efficacy and the use of reading strategies in the Chinese EFL context. Asian EFL Journal, 12(2), 144-162.

Lin, G. Y. (2016). Self-efficacy beliefs and their sources in undergraduate computing disciplines: An examination of gender and persistence. Journal of Educational Computing Research, 53(4), 540-561.

Lin, T. J., \& Tsai, C. C. (2017). Differentiating the Sources of Taiwanese High School Students' Multidimensional Science Learning Self-Efficacy: An Examination of Gender Differences. Research in Science Education, 1-22.

Magogwe, J. M. (2013). Metacognitive awareness of reading strategies of University of Botswana English as a second language students of different academic reading proficiencies. Reading and Writing, 4(1), 1-8. Retrieved from http://dx.doi.org/10.4102/rw.v4i1.29

Memis, A. \& Bozkurt, M. (2013). The relationship of reading comprehension success with metacognitive awareness, motivation, and reading levels of fifth grade students. Global Journal of Educational Foundation, 1(1), 034-038.

Mokhtari, K., \& Reichard, C. A. (2002). Assessing students' metacognitive awareness of reading strategies. Journal of educational psychology, 94(2), 249.

Mokhtari, K., \& Sheorey, R. (2002). Measuring ESL students' awareness of reading strategies. Journal of developmental education, 25(3), 2.

Naseri, M., \& Zaferanieh, E. (2012). The relationship between reading self-efficacy beliefs, reading strategy use and reading comprehension level of Iranian EFL learners. World Journal of Education, 2(2), 64.

Nosratinia, M., Saveiy, M., \& Zaker, A. (2014). EFL learners' self-efficacy, metacognitive awareness, and use of language learning strategies: how are they associated?. Theory and Practice in Language Studies, 4(5), 1080.

Pajares, F., Hartley, J., \& Valiante, G. (2001). Response format in writing self-efficacy assessment: Greater discrimination increases prediction. Measurement and evaluation in counseling and development, 33(4), 214. 
Pakistan Journal of Humanities and Social Sciences, 6(1), 2018

Phakiti, A. (2006). Modeling cognitive and metacognitive strategies and their relationships to EFL reading test performance. Melbourne Papers in Language Testing, 1, 53-95.

Phan, H. P. (2012). The development of English and mathematics self-efficacy: A latent growth curve analysis. The Journal of Educational Research, 105(3), 196-209.

Phan, H. P., \& Ngu, B. H. (2016). Sources of self-efficacy in academic contexts: A longitudinal perspective. School Psychology Quarterly, 31(4), 548.

Poole, A. (2011). The Online Reading Strategies Used by Five Successful Taiwanese ESL Learners. Asian Journal of English Language Teaching, 21.

Preacher, K. J., Rucker, D. D., \& Hayes, A. F. (2007). Addressing moderated mediation hypotheses: Theory, methods, and prescriptions. Multivariate behavioral research, 42(1), 185-227.

Rajab, H. (2013). Developing speaking and writing skills of L1 Arabic EFL learners through teaching of IPA phonetic codes. Theory and Practice in Language Studies, 3(4), 653659. http://dx.doi.org/10.4304/tpls.3.4. 653-659

Shang, H. F. (2010). Reading strategy use, self-efficacy and EFL reading comprehension. Asian EFL Journal, 12(2), 18-42.

Taghinezhad, A., Dehbozorgi, R., \& Esmaili, N. (2015). The influence of teaching metacognitive reading strategies on the reading self-efficacy beliefs of Iranian EFL learners: An experimental study. Modern Journal of Language Teaching Methods, $5(4), 728$

Tavakoli, H. (2014). The effectiveness of metacognitive strategy awareness in reading comprehension: The case of Iranian university EFL students. The Reading Matrix, 14(2), 314-336.

Tavakoli, H., \& Koosha, M. (2016). The effect of explicit metacognitive strategy instruction on reading comprehension and self-efficacy beliefs: the case of Iranian University EFL students. Porta Linguarum: revista internacional de didáctica de las lenguas extranjeras, (25), 119-133.

Tuncer, M., \& Dogan, Y. (2016). Relationships among Foreign Language Anxiety, Academic Self-Efficacy Beliefs and Metacognitive Awareness: A Structural Equation Modelling. International Journal of Learning and Development, 6(2), 31-41.

Uçar, S. B. (2016). The Exploration of the Relationship between Self-Efficacy and Strategy Use in a Turkish Context. Current Research in Education, 2(3), 186-198.

Veenman, M. V. J., \& Spaans, M. A. (2005). Relation between intellectual and metacognitive skills: Age and task differences. Learning and Individual Differences, 15, 159-176.

Veenman, M. V. J., Wilhelm, P., \& Beishuizen, J. J. (2004). The relation between intellectual and metacognitive skills from a developmental perspective. Learning and Instruction, $14,89-109$.

Webb-Williams, J. (2017). Science Self-Efficacy in the Primary Classroom: Using Mixed Methods to Investigate Sources of Self-Efficacy. Research in Science Education, 123.

Wigfield, A., Guthrie, J. T., Tonks, S., \& Perencevich, K. C. (2004). Children's motivation for reading: Domain specificity and instructional influences. The Journal of Educational Research, 97(6), 299-310.

Yailagh, M. S., Birgani, S. A., Boostani, F., \& Hajiyakhchali, A. (2013). The relationship of self-efficacy and achievement goals with metacognition in female high school students in Iran. Procedia-Social and Behavioral Sciences, 84, 117-119.

Yang, P. L., \& Wang, A. L. (2015). Investigation the Relationship among Language Learning Strategies, English Self-Efficacy, and Explicit Strategy Instructions. Taiwan Journal of TESOL, 12(1), 35-62. 
Yılmaz, C. (2010). The relationship between language learning strategies, gender, proficiency and self-efficacy beliefs: A study of ELT learners in Turkey. Procedia-Social and Behavioral Sciences, 2(2), 682-687.

Yuksel, I., \&Yuksel, I. (2012). Metacognitive awareness of academic reading strategies. Procedia - Social and Behavioral Sciences, 31, 894-898. http://dx.doi.org/10.1016/j.sbspro.2011.12.164

Yurt, E. (2014). The predictive power of self-efficacy sources for mathematics achievement. Egitim ve Bilim, 39(176).

Zarei, A. A., \& Gilanian, M. (2015). Self-efficacy as a function of language learning strategy use. British Journal of Education, Society \& Behavioural Science, 9(3), 223-235.

Zarei, A. A., \& Naghdi, F. (2017). Sources of Self-Efficacy as Predictors of EFL Learners' Course Performance. European Online Journal of Natural and Social Sciences, 6(1), pp-68.

Zhang, L., \& Seepho, S. (2013). Metacognitive strategy use and academic reading achievement: insights from a Chinese context. Electronic Journal of Foreign Language Teaching, 10(1), 54-69. 